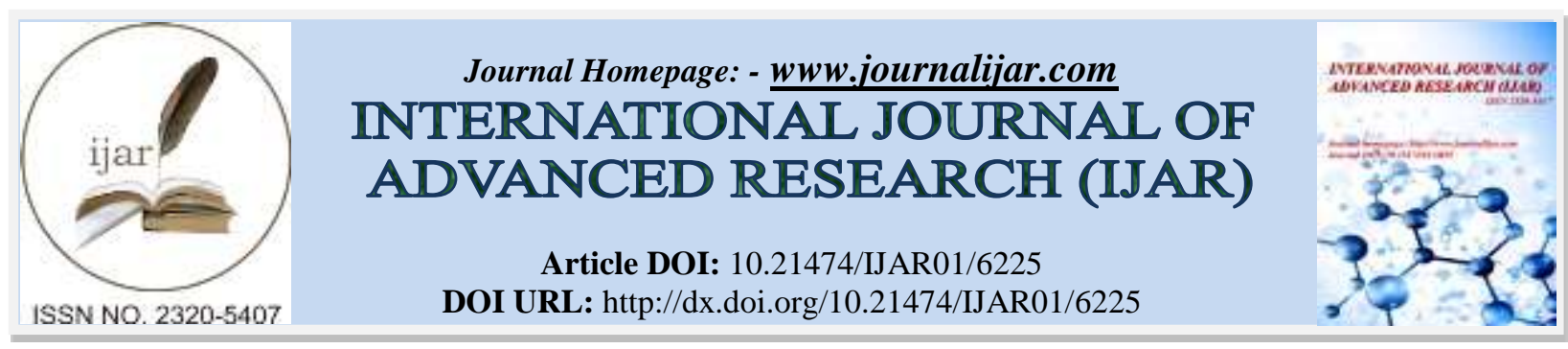

RESEARCH ARTICLE

\title{
BACTERIOLOGICAL PROFILE OF PATIENTS WITH ACUTE EXACERBATION OF COPD.
}

\author{
Dr. Abhishrut Pramod Jog ${ }^{1}$ and Dr. Theresia Risa Davita ${ }^{2}$. \\ 1. M.D. Medicine (Silchar Medical College \& Hospital, Assam, India), Medical Officer- Medipoint Hospital, \\ Pune, India. \\ 2. M.D. (Pelita Harapan University, Indonesia), Medical Officer, PT Mondrian Clinic, Central Java, Indonesia.
}

\section{Manuscript Info}

Manuscript History

Received: 05 November 2017

Final Accepted: 07 December 2017

Published: January 2018

\section{Abstract}

Copy Right, IJAR, 2018,. All rights reserved.

\section{Introduction:-}

Chronic obstructive pulmonary disease (COPD) constitutes about $30 \%$ of all the cases seen in chest clinics and accounts for 1- $2.5 \%$ of all hospital admissions in India (Arora N et al, 2001). As per W.H.O, It is the third leading cause of death worldwide behind ischemic heart disease and stroke (WHO, 2014). India contributes a significant percentage of COPD mortality which is estimated to be amongst the highest in the world, with about 556,000 (>20\%) out of a world total of 2,748,000 annually (Lopez AD et al, 2006).

Acute Exacerbations of COPD (AECOPD) are a prominent feature of the natural history of COPD. Exacerbations are defined as "An acute event characterized by a worsening of the patient's respiratory symptoms that is beyond normal day to day variations and leads to a change in medication" (GOLD, 2015).

Bacterial infection stands as one of the main precipitants of AECOPD (Chawla et al, 2008).

One of the components in the management of AECOPD is the use of antibiotics. It has been seen that the use of antibiotics provides a greater treatment success rate (Anthonisen et al, 1987) and a mortality benefit in AECOPD (Ram et al, 2006). The choice of antibiotics should be based on the local bacterial resistance pattern (GOLD,2015).

Silchar Medical College and Hospital is the only referral hospital in the southern part of Assam, and serves neighboring states including Mizoram, North Tripura, West Manipur and South Meghalaya. This study provides the bacterial etiology and sensitivity profile thus allowing the selection of appropriate empirical regimen of antibiotics for patients of acute exacerbations of COPD.

\section{Aims and Objectives:-}

1) To determine the bacteria causing acute exacerbations of COPD.1

2) To assess the antimicrobial sensitivity of the causative bacteria. 


\section{Methods and Materials:-}

\section{Study setting:-}

The study was conducted in the Department of Medicine, Silchar Medical College and Hospital, Silchar, Assam from $1^{\text {st }}$ June 2016 to $31^{\text {st }}$ May 2017 for a period of one year.

\section{Sample Size:-}

A total of 114 patients from the Out Patient Departments and In Patient Departments of the Department of Medicine, Silchar Medical College and Hospital, Silchar were included randomly for the study, after fulfilment of inclusion and exclusion criteria.

\section{Study Design:-}

The study was a hospital based cross-sectional observational study.

\section{Data Collection:-}

All the patients with clinical features suggestive of COPD, such as progressive dyspnoea, chronic cough, chronic sputum production with history of exposure to risk factors or a family history of COPD, were assessed. Out of these, the patients fulfilling the criteria for AECOPD were enrolled. AECOPD was diagnosed as per the following criteriaPresence of any two of the following symptoms (Anthonisen et al, 1987):

- Increased cough

- Increased purulence and / or volume of expectorations and

- Increased severity of dyspnoea.

These patients were immediately treated and stabilized. Informed and written consent was obtained from the patients.

A detailed clinical history was taken and complete physical examination was done in all cases. A spirometry was performed on all patients, along with bronchodilator reversibility testing. A post-bronchodilator $\mathrm{FEV}_{1} / \mathrm{FVC}$ of $<0.7$ confirmed the diagnosis of COPD as per the GOLD 2015 guidelines (GOLD, 2015). Routine investigations, Chest Radiograph, ECG were done in all the patients. CT scan of thorax was done in a few selected cases.

The data of such patients fulfilling the inclusion and exclusion criteria were collected on a structured proforma. Sputum samples were collected from all eligible patients for sputum culture and sensitivity testing. Processing and examination of the samples was done in the Department of Microbiology, Silchar Medical College and Hospital.

\section{Inclusion Criteria:-}

All patients above 18 years of age, diagnosed with COPD, as per GOLD criteria presenting with acute exacerbation, were included in the study.

\section{Exclusion Criteria:-}

All patients treated with antibiotics in the past 48 hours, known cases of malignancy or immunosuppression, tuberculosis, heart failure, pneumonia, asthma and unwilling patients, were excluded from the study.

\section{Ethical Clearance:-}

Ethical clearance for the study was taken from the Ethical Committee of Silchar Medical College and Hospital, Silchar, Assam (Date of approval- $13^{\text {th }}$ February 2015)

\section{Statistical Analysis:-}

The data were collected, compiled, tabulated and analyzed in terms of descriptive statistics using SPSS version 17.0 software. Continuous variables were presented as mean \pm SD and categorical variables were expressed as frequencies and percentages. Categorical data between the groups were compared using Chi square test. A p-value $<0.05$ was considered as statistically significant. Graphical and diagrammatic representations were made wherever felt necessary.

The following antibiotics were used in the antibiotic sensitivity testing. 


\section{Antibiotics used for Gram Positive Organisms were:-}

1) Vancomycin

2) Linezolid

3) Cefoxitin

4) Cefuroxime

5) Ceftriaxone

6) Azithromycin

7) Levofloxacin

8) Ciprofloxacin

9) Gentamycin

10) Amikacin

11) Amoxicillin- Clavulanic acid

12) Piperacillin Tazobactam

Antibiotics used for Gram Negative organisms were:-

1) Cefoperazone

2) Meropenem

3) Piperacillin-Tazobactam

4) Amikacin

5) Gentamycin

6) Levofloxacin

7) Ciprofloxacin

8) Ceftriaxone

9) Amoxicillin-Clavulanic Acid

10) Azithromycin

11) Imipenem

12) Cefuroxime

\section{Results \& Observations:-}

Out of the 114 cases, maximum number of cases were seen in the age groups of 56-65 years (42\%). The next commonest age group was $66-75$ years, with $20 \%$ of the cases. As many as $19 \%$ of the patients were between the ages of $46-55$ years. Other $13 \%$ cases were above the age of 75 years. Mean age was $62.9 \pm 10.7$ years.

There were 88/114 (77.2\%) males and 26/114 (22.8\%) females. The Male: Female ratio was 3.4:1.

There were 58/114 (50.9\%) farmers, 29/114 (25.4\%) day labourers, 13/114 (11.4\%) shopkeepers and 14/114 $(12.3 \%)$ housewives.

All patients (100\%) had dyspnoea on presentation. The next frequent presenting symptom was cough (95.6\%). Increased sputum volume was seen in $68.4 \%$ patients. Chest pain was seen in $34.2 \%$ and fever in $34.5 \%$ of the cases. Out of the 114 patients, bacteria were detected in 80 patients on microscopy. Out of these 80 patients, Gram positive bacteria were seen in $32.5 \%$ cases whereas Gram negative bacteria were seen in $67.5 \%$ cases.

There was a statistically significant association between purulence of sputum and frequency of isolation of bacteria (p-value < 0.05).

Total cases of Staphylococcus aureus isolated were 23. Out of these, MSSA (Cefoxitin Sensitive) cases were 16/23 (69.6\%). MRSA (Cefoxitin Resistant) were 7/23 (30.4\%). 
Table 1:- Association between nature of sputum and frequency of isolation of bacteria

\begin{tabular}{|c|c|c|c|c|}
\hline \multirow[t]{2}{*}{ Nature of Sputum } & \multicolumn{2}{|c|}{$\begin{array}{l}\text { Sputum Culture } \\
\text { (No. of cases) }\end{array}$} & \multirow[t]{2}{*}{ Total } & \multirow[t]{5}{*}{ P-value } \\
\hline & Sterile & Bacteria grown & & \\
\hline MUCOID & \begin{tabular}{|l|}
22 \\
$(61.1 \%)$
\end{tabular} & $\begin{array}{l}14 \\
(38.9 \%)\end{array}$ & $\begin{array}{l}36 \\
100 \%\end{array}$ & \\
\hline $\begin{array}{l}\text { MUCOPURULENT/ } \\
\text { PURULENT }\end{array}$ & $\begin{array}{l}12 \\
(15.4 \%)\end{array}$ & $\begin{array}{l}66 \\
(84.6 \%)\end{array}$ & $\begin{array}{l}78 \\
100 \% \\
\end{array}$ & \\
\hline Total & \begin{tabular}{|l|}
34 \\
$(29.8 \%)$
\end{tabular} & $\begin{array}{l}80 \\
(70.2 \%)\end{array}$ & $\begin{array}{l}114 \\
100 \%\end{array}$ & \\
\hline
\end{tabular}

Table 2:- Bacteriological profile

\begin{tabular}{|l|l|l|}
\hline Bacteria Isolated & No. of Cases & Percentage \\
\hline Klebsiella pneumonia & 37 & $46.25 \%$ \\
\hline Staphylococcus aureus & 23 & $28.75 \%$ \\
\hline Pseudomonas aeruginosa & 13 & $16.25 \%$ \\
\hline Acinetobacter species & 4 & $5 \%$ \\
\hline Streptococcus Pneumoniae & 3 & $3.75 \%$ \\
\hline Total & $\mathbf{8 0}$ & $\mathbf{1 0 0 \%}$ \\
\hline
\end{tabular}

Table 3:- Antibiotic sensitivity of isolated bacteria

\begin{tabular}{|c|c|c|c|c|c|c|c|c|c|c|c|}
\hline & \multicolumn{6}{|c|}{ Gram negative bacteria } & \multicolumn{4}{|c|}{ Gram positive bacteria } \\
\hline & & \multicolumn{2}{|c|}{$\begin{array}{l}\text { ACINETO- } \\
\text { BACTER }\end{array}$} & \multicolumn{2}{|c|}{$\begin{array}{l}\text { KLEBSIEL } \\
\text { LA }\end{array}$} & \multicolumn{2}{|c|}{$\begin{array}{l}\text { PSEUDOMON } \\
\text { AS }\end{array}$} & \multicolumn{2}{|c|}{$\begin{array}{l}\text { STAPH } \\
\text { AUREUS }\end{array}$} & \multicolumn{2}{|c|}{$\begin{array}{l}\text { STREP } \\
\text { PNEUMO }\end{array}$} \\
\hline \multicolumn{2}{|c|}{ Number for Culture } & \multicolumn{2}{|l|}{4} & \multicolumn{2}{|l|}{37} & \multicolumn{2}{|l|}{13} & \multicolumn{2}{|l|}{23} & \multicolumn{2}{|l|}{3} \\
\hline \multirow{16}{*}{ 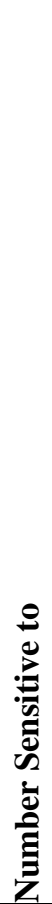 } & & No. & $\%$ & No. & $\%$ & No. & $\%$ & No. & $\%$ & No. & $\%$ \\
\hline & $\begin{array}{l}\text { CEFTRIAXON } \\
\text { E }\end{array}$ & 2 & 50 & 14 & 37.8 & 5 & 38.5 & 7 & 30.4 & 2 & 66.7 \\
\hline & CEFUROXIME & 1 & 25 & 9 & 24.3 & 3 & 23.1 & 8 & 34.8 & 1 & 33.3 \\
\hline & CEFOXITIN & - & - & - & - & - & - & 16 & 69.6 & 3 & 100 \\
\hline & AMOXCLAV & 1 & 25 & 24 & 64.9 & 7 & 53.8 & 13 & 56.5 & 3 & 100 \\
\hline & MEROPENEM & 3 & 75 & 36 & 97.3 & 12 & 92.3 & - & - & - & - \\
\hline & PIP TAZ & 3 & 75 & 36 & 97.3 & 11 & 84.6 & 19 & 82.6 & 3 & 100 \\
\hline & $\begin{array}{l}\text { LEVOFLOXAC } \\
\text { IN }\end{array}$ & 2 & 50 & 34 & 91.9 & 12 & 92.3 & 18 & 78.3 & 2 & 66.7 \\
\hline & $\begin{array}{l}\text { CIPROFLOXA } \\
\text { CIN }\end{array}$ & 1 & 25 & 16 & 43.2 & 7 & 53.8 & 14 & 60.9 & 2 & 66.7 \\
\hline & AMIKACIN & 2 & 50 & 34 & 91.9 & 12 & 92.3 & 21 & 91.3 & 3 & 100 \\
\hline & GENTAMYCIN & 2 & 50 & 20 & 54.1 & 10 & 76.9 & 15 & 65.2 & 3 & 100 \\
\hline & $\begin{array}{l}\text { VANCOMYCI } \\
\mathrm{N}\end{array}$ & - & - & - & - & - & - & 23 & 100 & 3 & 100 \\
\hline & LINEZOLID & - & - & - & - & - & - & 23 & 100 & 3 & 100 \\
\hline & $\begin{array}{l}\text { CEFOPERAZO } \\
\mathrm{NE}\end{array}$ & 2 & 50 & 31 & 83.8 & 11 & 84.6 & - & - & - & - \\
\hline & $\begin{array}{l}\text { AZITHROMYC } \\
\text { IN }\end{array}$ & 0 & 0 & 23 & 62.2 & 9 & 69.2 & 9 & 39.1 & 2 & 66.7 \\
\hline & IMIPENEM & 3 & 75 & 36 & 97.3 & 12 & 92.3 & - & - & - & - \\
\hline
\end{tabular}


Fig 1:- Bar diagram showing the antibiotic sensitivity pattern of all gram positive isolates

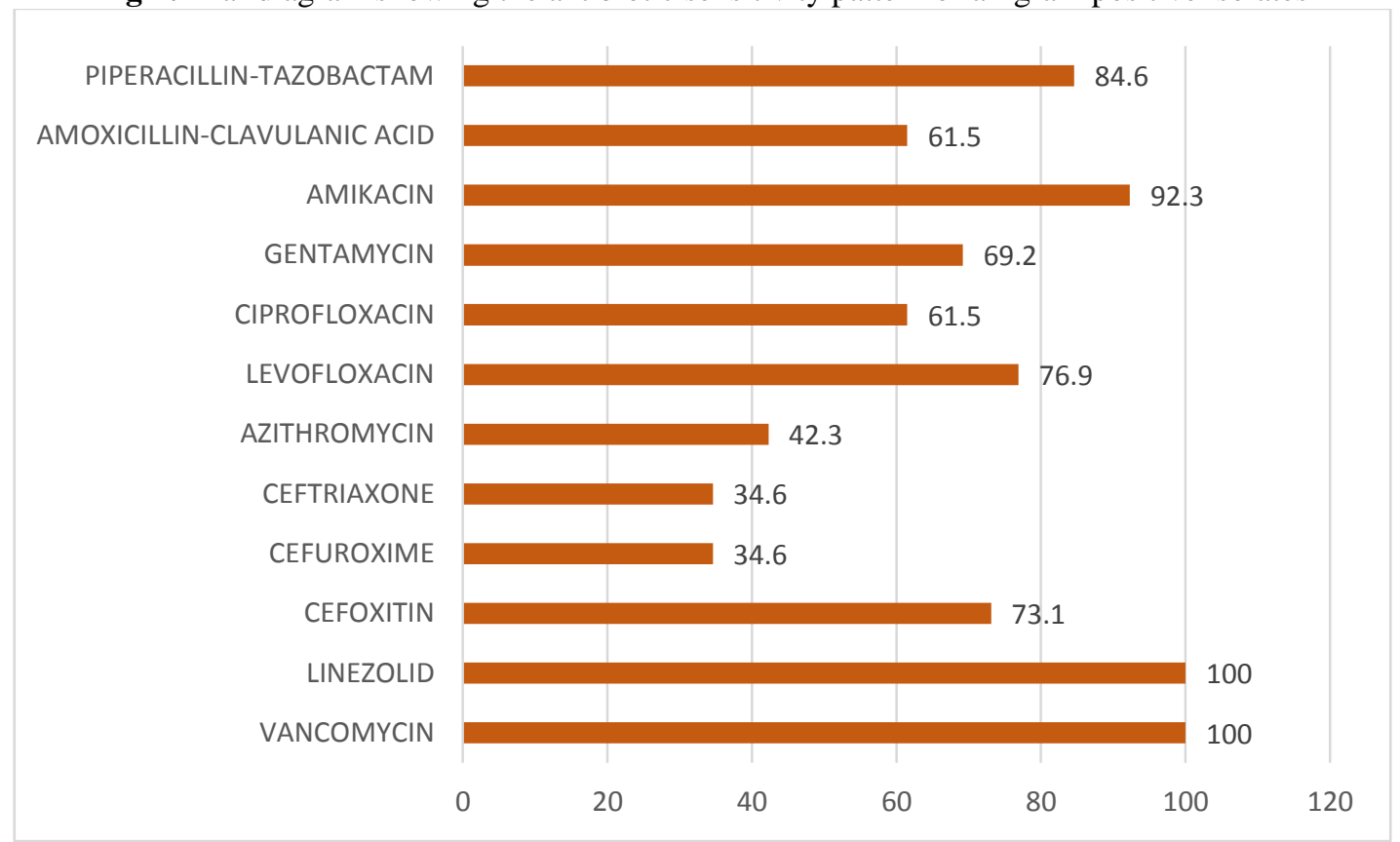

Fig 2:- Bar diagram showing the antibiotic sensitivity pattern of gram negative isolates

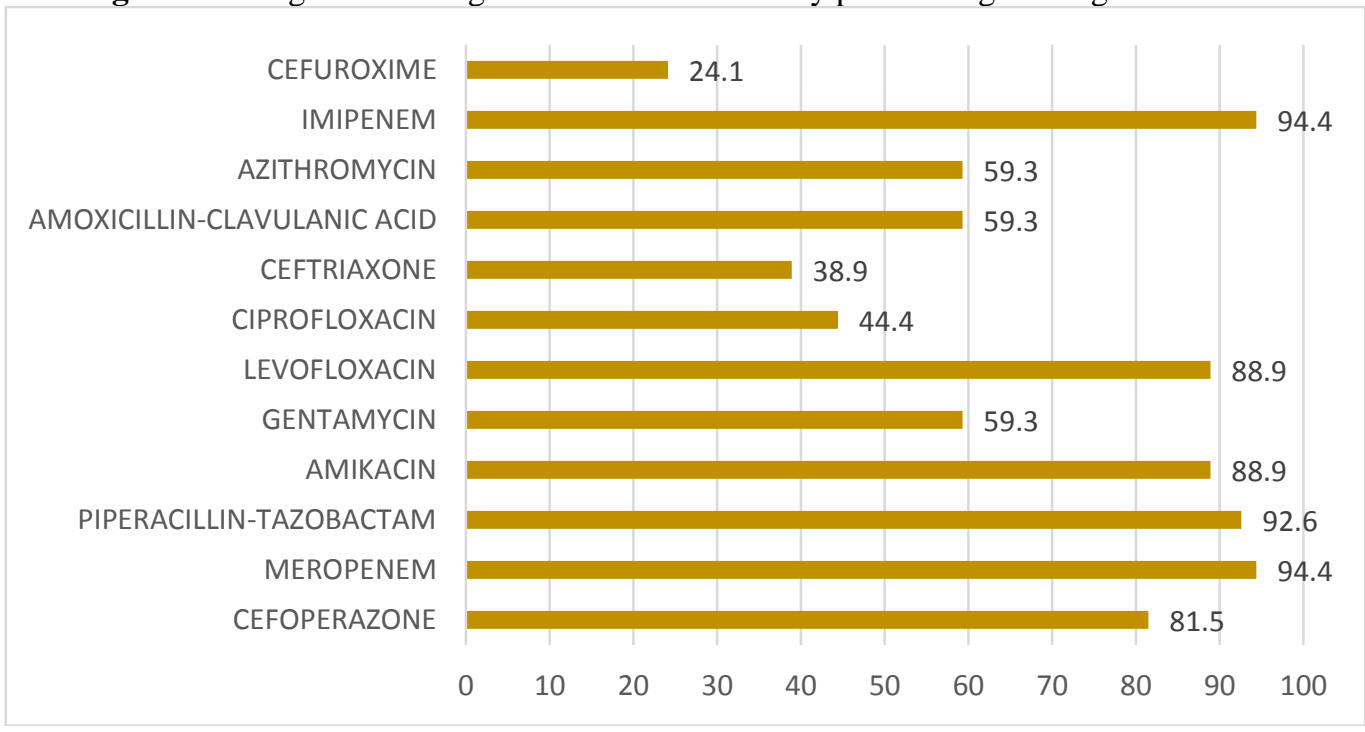

\section{Discussion:-}

Socio-demographic data:-

1) AGE

Age is often considered as among the risk factors of COPD. But whether healthy ageing by itself leads to COPD or it reflects the sum of cumulative exposures throughout life, is a debated issue (GOLD, 2015).

In the study conducted by Saikat Basu et al, similar to this study, majority of patients (33.33\%) were in the ages between 55-65 and 65-75 (Basu et al, 2013). In the other study, 40.19\% were in the age group of 55-65 (Narayanagowda et al, 2015). Mean age in the study by Shahanawaz et al was $59.42+10.59$ years (Shahanawaz A et al, 2003). 


\section{2) SEX}

A male preponderance, similar to the present study has been noted in other studies. In a study conducted in Kolkata, there were $76.2 \%$ male and $23.8 \%$ female cases. The ratio of Male:Female in that study was $3.2: 1$ (Basu et al, 2013). There were also around $79 \%$ male cases and $21 \%$ female cases that recorded in the other study (Madhavi et al, 2012). Miravitlles et al noted $81 \%$ males and 19\% females in their study (Miravitlles et al, 2000).

The higher number of males in the study may be a result of a higher number of males engaging in tobacco smoking as compared to females. The Global Adult Tobacco Survey revealed that $47.9 \%$ Indian males and $20.3 \%$ Indian females smoke tobacco (GATS, 2010).

The higher male prevalence in this study could also be a result of the greater financial independence, better disease awareness and the earlier seeking of medical attention of males in this part of the country.

\section{3) OCCUPATION}

The greater number of farmers in this study could be because this part of North-Eastern India primarily has agriculture based population.

\section{Bacteriological data:-}

\section{1) FREQUENCY OF ISOLATION OF BACTERIA}

Aleemullah et al in their study, reported $73.65 \%$ of samples as having bacterial growth (Aleemullah et al 2016). Kumar Surindar et al in 2012, reportedly found bacterial isolates in $67.14 \%$ in their study (Surindar et al 2012).

A lower frequency of isolation has been reported in a few other studies which are $13.33 \%$ and $41 \%$ (Shahanawaz et al, 2003), (Narayangowda et al, 2015).

The variation in the frequency of isolation of bacteria in the sputum in different studies could be the result of the differing methods of collection, time of collection, method of transportation, and also processing of the samples.

\section{2) DIFFERENTIATION BASED ON GRAM STAINING}

The greater frequency of isolation of Gram negative bacteria has been reported in other studies - 75\% (Madhavi et al, 2012), 71.42\% (Basu et al, 2013), 62.5\% (Shahnawaz et al, 2003), 62.39\% (Aleemulah et al, 2016), 57.7\% (Surindar et al, 2012), and 55\% (Narayanagowda et al, 2015).

\section{3) BACTERIOLOGICAL PROFILE}

In a study conducted in Kolkata, the commonest organism was found to be Klebsiella pneumoniae (33.33\%). The next organisms found, in decreasing order of frequency were- Staphylococcus aureus (29.6\%), Pseudomonas aeruginosa (19.05\%), and 9.51\% each for Escherichia coli and Acinetobacter species (Basu et al, 2013).

An old study in 1983 also reported the commonest organism in their study to be Klebsiella pneumoniae (39.2\%), followed by Staphylococcus aureus (28.57\%), and Pseudomonas aeruginosa (10.71\%). (Dalvi et al, 1983).

Klebsiella pneumoniae $(38.46 \%$ ) has been found as the commonest organism in a similar study. This was followed by Staphylococcus aureus (17.95\%), Streptococcus pneumoniae (15.38\%) and Pseudomonas aeruginosa (10.26\%). (Narayanagowda et al, 2015).

In 2012, a study on this subject reported the commonest bacteria isolated to be Klebsiella pneumoniae (59\%). The other organisms isolated were as follows- Pseudomonas aeruginosa (15\%), Staphylococcus aureus (13.6\%), Streptococcus pneumoniae (6.8) and 4.5\% Streptococcus pyogens (Madhavi et al, 2012).

Another 2015 study reported Klebsiella pneumonia as the commonest isolate (38.46\%), followed by Staphylococcus aureus (23.08\%), Streptococcus species (15.39\%), Pseudomonas aeruginosa (10.26\%), E. coli (5.13\%), Acinetobacter species (5.13\%) and Enterobacter species (2.56\%) (Sharan, 2015).

The current study thus correlates with the studies of Saikat Basu et al, Dalvi et al, Narayangowda et al, Madhavi S et al and Sharan et al. 


\section{4) ANTIBIOTIC SENSITIVITY}

In the study by Basu et al, it was seen that the Gram negative isolates, Klebsiella pneumoniae and Pseudomonas aeruginosa, showed the highest sensitivity to Meropenem (100\%), Imipenem (90\%), Amikacin (89\%), Cefoperazone $(86 \%)$ and Levofloxacin (80\%). Also, in the study, the Gram positive isolate- Staphylococcus aureus showed the highest sensitivity (100\%) to Vancomycin, Linezolid, and Piperacillin-Tazobactam (Basu et al, 2013).

Similar antibiotic sensitivity patterns were also seen in the study by Aleemullah et al. It was seen that Klebsiella pneumoniae was highly sensitive to Imipenem (100\%), Piperacillin-Tazobactam (100\%) and Amikacin (81\%). A very low sensitivity was seen for the Cefuroxime (18.18\%). In the same study, Pseudomonas aeruginosa was seen to be highly sensitive to Imipenem (84.21\%), Piperacillin-Tazobactam (84.21\%) and Amikacin (78.95\%). In the case of Pseudomonas aeruginosa, the sensitivity to Cefuroxime was seen in a minority of cases (47.37\%). Staphylococcus aureus was shown to be highly sensitive to Vancomycin (100\%), Linezolid (100\%) and also to PiperacillinTazobactam (87.5\%) and Amikacin (75\%). In case of Staphylococcus aureus, Cefuroxime sensitivity was seen in only a minority of cases (12.5\%). Streptococcus pneumoniae, was found to have the highest sensitivity to Vancomycin (100\%) and Linezolid (100\%) and also to Amikacin (84\%), Piperacillin-Tazobactam (88\%) and Gentamycin (76\%) (Aleemullah et al, 2016).

A 2012 study, found that Klebsiella pneumoniae isolates in their study were most sensitive to Meropenem (86\%) and Piperacillin-Tazobactam (76\%). Pseudomonas aueruginosa isolates were most sensitive to Meropenem (87\%) and Amikacin (79\%). Staphylococcus aureus showed highest sensitivity to Vancomycin (100\%). Acinetobacter species was sensitive to Meropenem in $66 \%$ cases, which was one of the antibiotics it was most sensitive to (Surindar et al, 2012).

A 2015 study also found that in case of Gram negative organisms high sensitivities were seen for PiperacillinTazobactam (100\%), Cefoperazone (100\%) and Amikacin (92.68\%). Streptococcus pneumonia was found to be highly sensitive $95.83 \%$ to Piperacillin-Tazobactam (Patel et al, 2015).

In another study from 2012, Pseudomonas aeruginosa was found to be highly sensitive to Levofloxacin (100\%) and Amikacin (100\%), similar to present study. Klebsiella pneumoniae was found to be sensitive to Amikacin (100\%) and Levofloxacin (92\%), correlating with the present study (Madhavi et al, 2012).

Narayangowda et al found that Pseudomonas aeruginosa showed high sensitivity to Piperacillin-Tazobactam and Amikacin, whereas Streptococcus pneumonia showed high sensitivity to Gentamycin and Amikacin (Narayanagowda et al, 2015).

5) PROPORTION OF MRSA

A study in 2015 found $28.5 \%$ of total Staphylococcus aureus isolates to be MRSA (Narayanagowda et al, 2015).

\section{Association between Nature of Sputum and frequency of isolation of bacteria:-}

The frequencies of isolation of bacteria in mucoid sputum as reported in a few other studies were as follows: Arora et al- $25 \%$, Aleemullah et al- $41.67 \%$, and Patel et al- $68.97 \%$. In these studies, the frequencies of isolating bacteria from mucopurulent / purulent sputum samples were as follows: Arora et al- 85\%, Aleemullah et al- $83.93 \%$ and Patel et al- $100 \%$. Thus, frequency of isolating a bacteria increased with purulent sputum compared to mucoid (Arora et al,2001), (Aleemullah et al,2016), (Patel et al, 2015), which corroborates with the present study.

\section{Conclusions:-}

It is concluded from the present study that bacterial infection is a major cause of AECOPD. Gram negative bacteria are seen predominantly. Klebsiella pneumoniae is the commonest bacteria, precipitating AECOPD.

The other important organisms are Staphylococcus aureus, Pseudomonas aeruginosa, Acinetobacter species and Streptococcus pneumoniae.

Sputum purulence is indicative of bacterial infection in majority of the cases

Antibiotics showing high activity against Gram negative organisms are Meropenem, Imipenem, PiperacillinTazobactam, Amikacin and Levofloxacin. 
Antibiotics showing high activity against Gram positive organisms are Vancomycin, Linezolid, Amikacin and Piperacillin-Tazobactam.

\section{References:-}

1. Aleemullah MF, V.Krishnamurthy, M.Harish and C.Arshad Akeel. Bacteriological Profile of Patients with AECOPD- Hospital Based Study. Int J Curr Microbiol App Sci. 2016; 5: p. 84-90.

2. Anthonisen NR, Manfreda J, Warren CP, Hershfield ES, Harding GK, Nelson NA. Antibiotic therapy in exacerbations of chronic obstructive pulmonary disease. Ann Intern Med. 1987; 106: p. 196-204.

3. Arora N, M.K. Daga, R Mahajan, S Krishna Prakash . Microbial pattern of Acute Infective Exacerbation of Chronic Obstructive Airway Disease in a hospital based study. Indian J Chest Dis. Allied Sci. 2001; 43: p. 157162

4. Basu S, Mukherjee S, Samant A. Epidemiological Study of Bacterial Microbiology in AECOPD patients of Kolkata India. Asian J Pharm Clin Res. 2013; 6: p. 112-116.

5. Chawla K, Mukhopadhay C, Majumdar M, Bairi I . Bacteriological Profile and their Antibiogram from Cases of Acute Exacerbations of Chronic Obstructive Pulmonary Disease: A Hospital Based Study. Journal of Clinical and Diagnostic Research. 2008; 2: p. 612-616.

6. Dalvi S, Bhave G G, Bhatt A D, Wagle N N, Dalvi C P. Chronic bronchitis : Part I. A bacteriological study of acute exacerbation. J Postgrad Med. 1983; 29.

7. Global Adult Tobacco Survey. ; 2010.

8. GOLD. Global strategy for the diagnosis, management and prevention of chronic obstructive pulmonary disease. Global Initiative of Chronic Obstructive Lung Disease 2015. 2015.

9. Lopez AD, Shibuya K, Rao C, Mathers CD, Hansell AL, Held LS, et al. Chronic obstructive airway disease: Current burden and future projections. Eur Resp J. 2006;(27): p. 397-41.

10. Madhavi S, Rama Rao M V , Janardhan Rao R . Bacterial etiology of acute exacerbations of chronic obstructive pulmonary disease. J Microbiol Biotech Res. 2012; 2: p. 440-444.

11. Miravitlles M, Guerrero T, Mayordomo C, Sánchez-Agudo L, Nicolau F, Segú JL.Factors associated with increased risk of exacerbation and hospital admission in a cohort of ambulatory COPD patients: a multiple logistic regression analysis. The EOLO Study Group. Respiration. 2000; 67: p. 495-501.

12. Narayanagowda DS, Saroj Golia, Jyoti Jaiswal, Suhani Srinivas Manasa. A bacteriological study of acute exacerbation of chronic obstructive pulmonary disease over a period of one year. Int J Res Med Sci. 2015; 3: p. 3141-3146.

13. Patel AK, Luhadia AS, Luhadia SK . Sputum Bacteriology and Antibiotic Sensitivity Pattern of Patients Having Acute Exacerbation of COPD in India - A Preliminary Study. J Pulm Respir Med. 2015; 5:238. doi:10.4172/2161-105X.1000238.

14. Ram FSF, Rodriguez-Roisin R, Granados-Navarrete A, Garcia-Aymerich J, Barnes NC . Antibiotics for exacerbations of chronic obstructive pulmonary disease. Cochrane Database Syst Rev. 2006; 2: CD004403.

15. Shahnawaz A, SM Saleem, Mushtaq A Lone Shah Sonaullah Tariq Bhat, Gh. Bhat, Gh. Nabi Dhobi. Bacteriological Profile in Acute Exacerbation of Chronic Obstructive Pulmonary Disease. JK Practitioner. 2003; 10: p. 185-187.

16. Sharan H. Aerobic Bacteriological Study of Acute Exacerbation of Chronic Obstructive Pulmonary Disease. Journal of Clinical and DIagnostic Research. 2015: p. 10-12.

17. Surindar K, Megha V, Singh Varsha A., Mehta Sonia, Jad Beena, Bareja Rajesh . Bacteriological Profile of Sputum and their antibiogram in cases of Acute Exacerbations of Chronic Obstructive Pulmonary Disease from a rural Tertiarycare hospital. Journal of Advance Researches in Biological Sciences. 2012; 4: p. 115-119.

18. www.who.int. [Online].; 2014. Available from: http://www.who.int/mediacentre/factsheets/fs310/en/. 